\title{
Information technology portfolio in supply chain management using factor analysis
}

\author{
Ahmad Jaafarnejad ${ }^{a}$, Davood Rafierad ${ }^{b^{*}}$ and Masoumeh Gardeshi $^{\mathrm{c}}$
}

${ }^{a}$ Professor, Management Department, University of Tehran, Tehran, Iran

${ }^{b} \mathrm{PhD}$ Candidate of Industrial Management, University of Tehran, Tehran, Iran

${ }^{c}$ Master of Industrial Management, Allameh Tabataba'i University, Tehran, Iran

C H R O N I C L E

Article history:

Received May 12, 2013

Received in revised format

12 August 2013

Accepted 28 September 2013

Available online

October 22013

Keywords:

Information technology

Supply chain management

Factor analysis

IT criteria

\begin{abstract}
A B S T R A C T
The adoption of information technology (IT) along with supply chain management (SCM) has become increasingly a necessity among most businesses. This enhances supply chain (SC) performance and helps companies achieve the organizational competitiveness. IT systems capture and analyze information and enable management to make decisions by considering a global scope across the entire SC. This paper reviews the existing literature on IT in SCM and considers pertinent criteria. Using principal component analysis (PCA) of factor analysis (FA), a number of related criteria are divided into smaller groups. Finally, SC managers can develop an IT portfolio in SCM using mean values of few extracted components on the relevance emergency matrix. A numerical example is provided to explain details of the proposed method.
\end{abstract}

(C) 2013 Growing Science Ltd. All rights reserved.

\section{Introduction}

Supply chain management (SCM) has come to the forefront of organizational practice as company's link to their suppliers electronically, to form inter-functional operations within their organizations and to forge electronic connections with some key customers (Byrd \& Davidson, 2003). In an effort to achieve this, many companies have decentralized their value-adding activities by outsourcing and developing virtual enterprise. All these highlight the importance of information technology (IT) in integrating suppliers/partnership firms in virtual enterprise and supply chain (SC) (Gunasekaran \& Ngai, 2003). Organizations increasingly depend on IT to improve the SC process. Indeed, manufacturers are increasingly dependent on the benefits brought about by IT to: improve SC agility, to reduce cycle time, to achieve higher efficiency, and to deliver products to customers in a timely manner (Radjou, 2003).

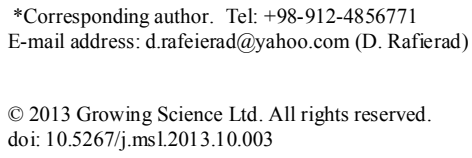


The implementation of IT in the SC can enable a firm to develop and to accumulate knowledge stores about its customers, suppliers, and market demands, which in turn influences firm performance (Tippins\& Sohi, 2003). IT is an essential enabler of effective SCM (Gunasekaran, \& Chung, 2004; Simchi-Levi et al., 2000), business process excellence (Davenport, 1993), and global competition success (Ngai et al., 2008). Since business transactions about purchasing, production, shipment, and payment accounts for a large volume of a firm's daily business, ensuring the operational information is recorded and shared seamlessly and it is critical for operational efficiency and responsiveness in supply chains (Lee, 2002).

Considering the relative importance of IT in achieving effective SCM, an attempt has been made by Gunasekaran and Ngai (2003) to review the literature on IT in SCM based on suitable criteria to identify the critical success factors of IT for an integrated SC. The main objective of their paper is to identify the major issues surrounding the application of IT in SCM, and develop a framework for IT applications in SCM. This paper aims to introduce an application of factor analysis (FA) for illuminating and classifying IT pertinent criteria in SCM, which brought out by Gunasekaran and Ngai (2003). The detailed objectives of this study are:

- To propose a tactical methodology that enables academia and managers to classify diverse and obscure information at an exploratory stage of research and/or tasks (e.g. diverse IT activities related to $\mathrm{SCM})$.

- To propose a methodology that allows practitioners to determine IT portfolio for SCM based on a relevance-emergency matrix.

The organization of the paper is as follows: Section 2 discusses the IT in SCM and FA. Section 3 presents the classification scheme used for reviewing the selected literature available on IT in SCM. The details of the research methodology and a case example are presented in Section 4. Finally, conclusions are presented in Section 5.

\section{Definitions and techniques}

\subsection{IT in SCM}

IT focuses on information management tools and functions that integrate procurement, operations, and logistics from raw materials to customer satisfaction in SC. Further, it increases manufacturing flexibility, transportation speed, and information availability, as well as management complexity. In recognition of these challenges, practicing managers and academic researchers have realized that SCM has been a major component of competitive strategy to enhance organizational productivity and profitability (Su \& Yang, 2010).

The IT in SC influences firm performance in several ways. First, an integrated system helps to achieve benefits through allowing a firm to respond better to customer problem and requests (Rogers et al., 1993). Second, information flows facilitated by the IT can potentially increase the sales volume by reaching customers directly and promptly whenever a new product is introduced, and by tapping into markets that were inaccessible on account of distribution or other infrastructure constraints (Wu et al., 2003). Third, IT can help firms reduce transaction costs and enhance collaboration efficiency among SC partners (Chae et al., 2005). Therefore, IT enabled SCM is at the core of operational strategies for firms to manage both their internal operation efficiency and their external relationships, particularly the crosscompany workflow, in a SC (Manecke \& Schoensleben, 2004; Gunasekaran \& Chung, 2004). Fig. 1 shows the key relationships among IT, operations management, and SCM in firms. 
Supply Chain Management

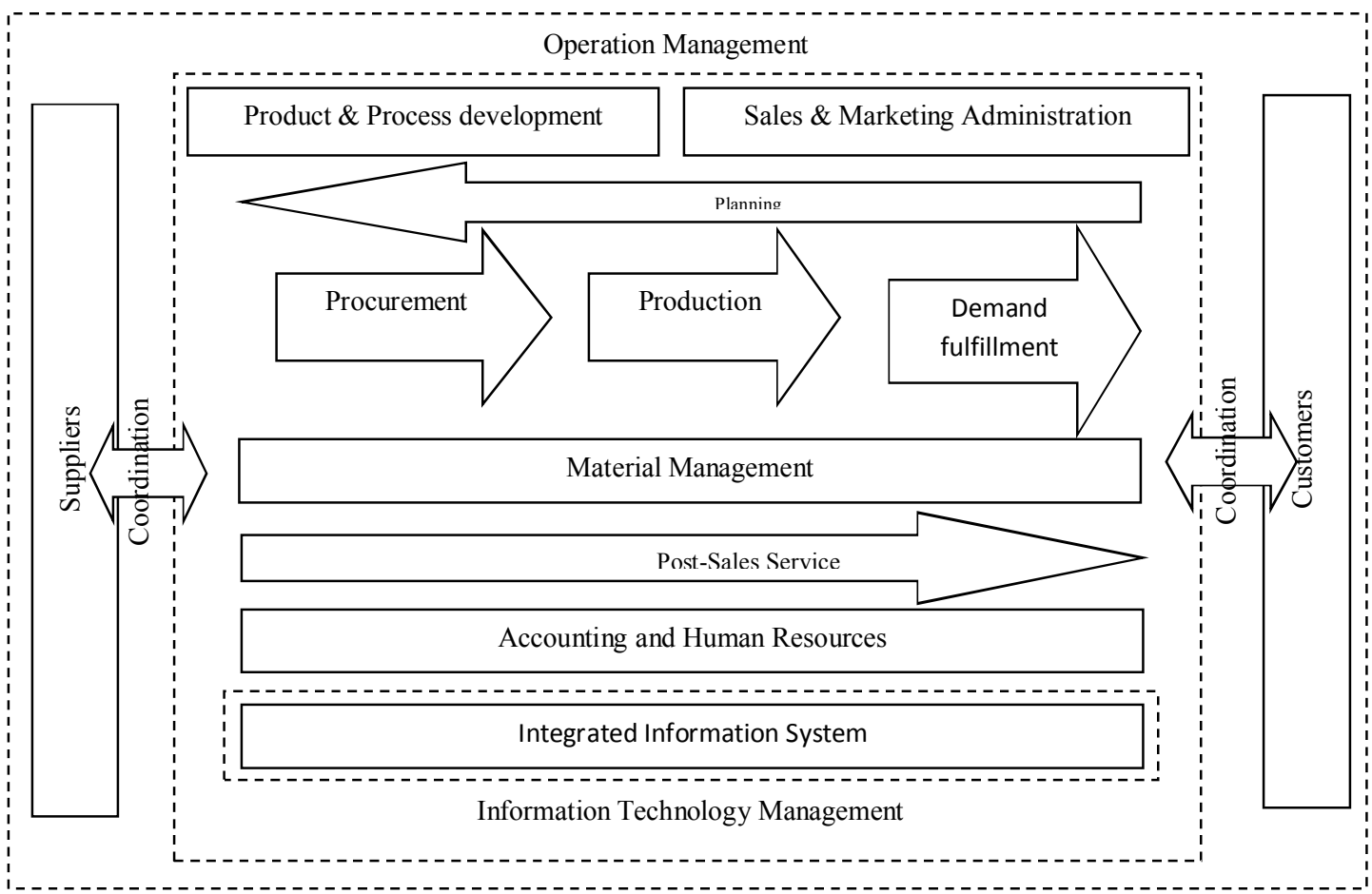

Fig. 1. The relationship between firms' IT management, operations management and SCM from IT perspective, adapted from SAP Inc's presentation slides (Zhang \& Dhaliwal, 2009)

\subsection{Factor Analysis}

FA refers to a variety of statistical techniques whose common objective is to represent a set of variables in terms of a smaller number of hypothetical variables. FA helps convert a large number of variables into a smaller number of variables, called factors, which capture as much information as possible from the original data set (Parasuraman et al., 2004). As an interdependence statistic tool, FA is based on three main assumptions (Jolliffe, 2002):

- Variables are linearly related to each other,

- Data are interval scaled,

- The rating given to any one variable (called factor loading) is partially the result of the influence of other variables.

Depending on the purpose of factor analysis, principal component analysis (PCA) or common factor analysis (CFA) are used as analysis model. The former is applied when a survey's purposes to reduce a large number of initial variables into a possibly small number of variables for forecasting while the latter is used when a survey aims to find out correlations among variables (Parasuraman et al., 2004). In this paper, we use the (PCA) as analysis model.

\subsubsection{Principle component analysis (PCA)}

The PCA involves a data and variable reduction technique in that a large number of interrelated variables are transformed into a small number of correlated new set of variables called principal components (PCs) or factors (Jolliffe, 2002). It is one of multivariate analysis techniques based on eigenvectors of a covariance matrix and is used as data extraction method for FA. PCA analyzes data using total variance (common variance, specific variance and error measurement) for extraction of correlated factors among original data (Lee, \& Lee, 2011). 
For the calculation of PCA, we act as follows:

First, the mean has to be subtracted from each of the data dimensions, and then we have to calculate the covariance matrix. Second, eigenvectors and eigen values have to be calculated (Smith, 2000)

\section{Literature review}

\subsection{Strategic planning for IT in SCM}

Strategic planning of IT should support the long-term objectives and goals of SCM both in terms of flexibility and responsiveness to change market requirements (Gunasekaran \& Ngai, 2003). Andersen (2001) presented a study of IT, strategy decision making and organizational performance. Andersen noted that Strategic-level planning involves supply-chain network design, which determines the location, size, and optimal numbers of suppliers, production plants, and distributors to be used in the network.

Daniels (1998) argued that information systems and technology could be centrally instrumental in achieving corporate goals. However, the organizations need to have a clearly defined corporate and competitive strategy, and should understand the information needed for underpin these strategies.

Cerpa and Verner (1998) presented a longitudinal study of the information systems strategic planning process (ISSP) within a large Australian organization. They discussed ISSP with regard to its strategic relevance, factors affecting IS strategic planning, key issues in ISSP, the effects of infusion and diffusion levels, together with the effect of IS maturity on ISSP.

Lockamy and Smith (1998) in their study argued that the application of information technology needs facilitating process management, strategy-process-customer alignment adjustments, and communications with internal and external customers. Henderson and Venkataraman (1993) discussed analytical and administrative approaches for conceptualizing and managing the emerging nexus between strategic management and information technology. They discussed the analytical approach through their strategic alignment model - defined in terms of four basic domains of strategic choice: business strategy, information technology strategy; organization infrastructure and processes, and information technology infrastructure and processes.

\subsection{Virtual enterprise in SCM}

Virtual enterprise (VE)/virtual organization (VO) is based on developing a network of collaborative firms with necessary core competencies for reaching the market on time with right products. Developing a network of firms requires a communication system to achieve a co-operative supported work. This could be achieved by utilizing various telecommunication technologies. That is IT is so important in developing and operating a VE/VO (Gunasekaran \& Ngai, 2003).

Clements (1997) in his study "Standards support for the virtual enterprise," noted that recent developments in global commerce have witnessed the advent of the virtual enterprise. The extended enterprise and the virtual enterprise are able to see in the context of enterprise partnerships, designed to facilitate co-operation and integration across the value chain (Browne \& Zhang, 1999). Some of the key factors in virtual enterprise development are IT-enabled SCM, partnership, virtual enterprise and $\mathrm{SC}$, and virtual enterprise and IT.

\subsection{E-commerce and SCM}

E-commerce has led to potential for information transparency in the SC (Naim, 2006). The advent of e-commerce has made SCM and time-based competition, from an operational perspective, even more 
critical. The selection of an appropriate system, vendor, platform, and media helps for the integration of business-to-business (B2B) operations and systems (Sarkis \& Talluri, 2004). E-commerce may be defined as "any form of business transaction in which the parties interact electronically rather than by physical exchanges or direct physical contact" (Turowski, 2002). It "refers to business activities involving consumers, manufacturers, service providers, and intermediaries using computer networks such as the Electronic Data Interchange (EDI), direct link-ups with suppliers, Internet, Intranet, Extranet, electronic catalog ordering, and e-mail" (Lancioni et al., 2000). McIvor et al. (2000) showed how e-commerce could fundamentally change the inter-organizational processes at the interface between the buyer and supplier. They also showed how e-commerce was not only enabling the redesign of internal organizational processes but it was extended into both the buyer and supplier organizations.

\subsection{Infrastructure for IT in SCM}

Infrastructure for IT in SCM consists of internet connectivity, hardware and software including application systems integration (Gunasekaran \& Ngai, 2003). IT infrastructure integration are defined as the degree in which a focal firm has established IT capabilities for the consistent and high-velocity transfer of SC-related information within and across its boundaries (Angeles, 2009). Rai et al. (2006) defined IT infrastructure integration in terms of two sub constructs, data consistency and crossfunctional SCM application systems integration.

In evaluating the formation of customer-supplier relationships, Sarkis and Sundararaj (2002) concentrated on two major dimensions, which would influence the formation process. The first is the type of organizational structure and relationships, and the second major dimension is the e-commerce environment. Jayaram et al. (2000) presented an empirical study of 57 top tier suppliers to the North American automotive industry and examined the direct and complementary effects of information system infrastructure and process improvements on time-based performance.

\subsection{Knowledge and IT management in SCM}

Knowledge management (KM) is a major enabler of SCM, and it is a critical element in information intensive and multi-cultured enterprise environments (Samuel et al., 2011). The flows of information lying at the core of the coordination and collaboration among network members are not only disparate information sources, but also it provides an opportunity to build knowledge-based tools that are an important part of the extended firm's capabilities (Davis \& Spekman, 2004).

In a globalization context, knowledge transparency brings new objectives of providing more detailed product information to the consumer and gathers more detailed knowledge about the individual consumer (Leidner, 2010). These new challenges underscore that SC could be considered as a cradle of knowledge because they involve multiple autonomous players with varying technical cultures, managerial backgrounds and SCM exposure. Increasingly, scholars see development of a knowledge based SC as an opportunity to achieve better value for customers (Wadhwa \& Saxena, 2005). The literature review shows two main streams of research regarding inter-organizational knowledge: some reports have concentrated on learning issues within networks and have tried to identify different types of learning, which might take place within SC, while other research mainly focuses on knowledge creation and KM practices in the specific context of a SC (Samuel et al., 2011).

\subsection{Implementation of IT in SCM}

Implementation of IT in SCM can integrate and coordinate the flow of materials, information, and finances among suppliers, manufacturers, wholesalers, retailers and end-consumers (Li et al., 2009). Methodological issues of IT implementation in SCM indicate the approach employed. For example, some companies choose to reengineer their business process with the objective of implementing IT 
and hence improve their performances; also, project management and planning method were used to implementing of IT in SCM (Gunasekaran \& Ngai, 2003). There are different tools that could be used for the implementation of IT in SCM and some of them include (i) quality function deployment, (ii) concurrent engineering, and (iii) life cycle approach (Scott, 1996). Pawar and Driva (2000) highlighted six major issues in the implementation of EDI in SC environment to improve the success of the implementation framework that include the following steps: (i) develop strategy, (ii) assessment, (iii) create culture, (iv) priority improvements, (v) plan the change, (vi) implement improved situation and support implementation. Cooper and Zmud (1990) proposed a technological diffusion approach for IT implementation. In the networked and collaborative enterprise environment, this diffusion approach will be appropriate.

Human factors such as the behavioral attitude towards the implementation of IT in SCM, level of education, knowledge in computers, international exposure, training and education, reward and employee empowerment and incentive scheme influence the successful implementation of IT in SCM (Gunasekaran \& Ngai, 2003).

\section{Methodology}

The proposed methodology in this article consists of these steps (see Diagram.2).

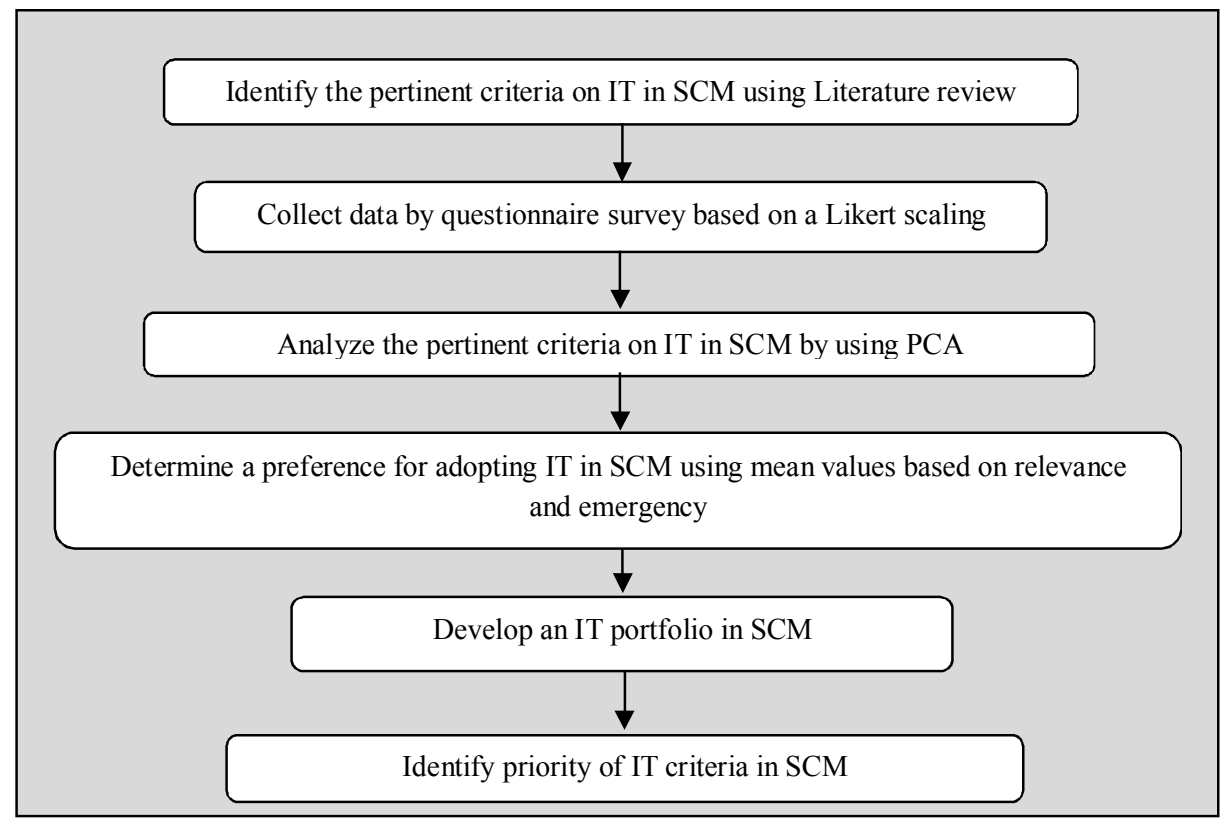

Fig. 2. The proposed methodology

\subsection{Data collection and listing of criteria on IT in SCM}

First, the pertinent criteria on IT in SCM are identified using literature review and enumerating every possible criterion that describes activities (variables) for the development on IT for effective SCM. Sixteen criteria on IT in SCM were suggested in Table 1 as initial variables.

\subsection{Questionnaire survey}

Experts are asked about the implementation level of various areas of IT in SCM. The respondents estimate their IT in SCM criteria using a questionnaire sheet based on a Likert scaling. Respondents 
indicated their agreement with each variables, using five-point scales ( $5=$ extremely important, $4=$ very important, $3=$ =important, $2=$ somewhat important, $1=$ not important).

\section{Table 1}

Criteria on IT in SCM on IT in SCM

1) Strategic marketing reasons of IT in SCM

2) Strategic economic reasons

3) Organizational strategic planning

4) Technological strategic planning

5) Virtual enterprise and IT in SCM

6) Partnership in Virtual enterprise

7) Purchasing in e-commerce

8) $\mathrm{B} 2 \mathrm{~B}$ e-commerce

9) Logistics in e-commerce

10) Organizational infrastructure for IT in SCM

11) Technological infrastructure for IT in SCM

12) Technology management in Knowledge and IT management in SCM

13) Education and training Knowledge and IT management in SCM

14) Organizational implementation of IT in SCM

15) Methodological implementation of IT in SCM

16) Human resource in implementation of IT in SCM

\subsection{Analysis of criteria on IT in SCM}

A large number of collected data based on the criteria of IT in SCM are analyzed by using PCA as data extraction method. First, the mean value has to be subtracted from each of the data dimensions. Then, initial eigenvalue and extraction sums of squared loadings in total variance are calculated. The squared loadings with orthogonal factor rotation allow identification the number of few components and reliability of the extracted components. The Statistical Package for Social Science (SPSS) was utilized to conduct FA and other statistical analysis. The primary results of FA presented as follows: The result of KMO (a measure of sampling adequacy should be greater than 0.5) test for all the variables was 0.772 , which is acceptable for FA (Kim et al., 1987). Table 2 demonstrates eigenvalues, percent of variance, and cumulative percent in three types such as initial eigenvalues, extraction sums of squared loading, and rotation sums of squared loading. Six components are finally extracted based on latent root criterion, which defines eigenvalues more than 1.

Table 2

Total variance explained using PCA (Extraction method: principal component analysis)

\begin{tabular}{|c|c|c|c|c|c|c|c|c|c|}
\hline \multirow{2}{*}{ Component } & \multicolumn{3}{|c|}{ Initial eigenvalues } & \multicolumn{3}{|c|}{ Extraction sums of squared loadings } & \multicolumn{3}{|c|}{ Rotation sums of squared loadings } \\
\hline & Total & $\begin{array}{c}\% \text { of } \\
\text { variance }\end{array}$ & Cumulative \% & Total & $\begin{array}{c}\% \text { of } \\
\text { variance }\end{array}$ & Cumulative \% & Total & $\begin{array}{c}\% \text { of } \\
\text { variance }\end{array}$ & $\begin{array}{c}\text { Cumulative } \\
\%\end{array}$ \\
\hline 1 & 5.012 & 28.761 & 28.761 & 5.012 & 28.761 & 28.761 & 2.912 & 14.508 & 14.508 \\
\hline 2 & 3.313 & 16.020 & 44.781 & 3.313 & 16.020 & 44.781 & 2.865 & 13.863 & 28.371 \\
\hline 3 & 1.968 & 10.442 & 55.223 & 1.968 & 10.442 & 55.223 & 2.745 & 13.110 & 41.481 \\
\hline 4 & 1.788 & 7.829 & 63.052 & 1.788 & 7.829 & 63.052 & 2.566 & 12.745 & 54.226 \\
\hline 5 & 1.490 & 6.984 & 70.036 & 1.490 & 6.984 & 70.036 & 2.122 & 11.442 & 65.668 \\
\hline 6 & 1.164 & 5.391 & 75.427 & 1.164 & 5.391 & 75.427 & 1.895 & 9.759 & 75.427 \\
\hline 7 & 0.981 & 4.577 & 80.004 & & & & & & \\
\hline 8 & 0.858 & 4.392 & 84.396 & & & & & & \\
\hline 9 & 0.794 & 3.249 & 87.645 & & & & & & \\
\hline 10 & 0.683 & 2.725 & 90.370 & & & & & & \\
\hline 11 & 0.633 & 2.388 & 92.758 & & & & & & \\
\hline 12 & 0.512 & 1.975 & 94.733 & & & & & & \\
\hline 13 & 0.398 & 1.667 & 96.400 & & & & & & \\
\hline 14 & 0.273 & 1.483 & 97.883 & & & & & & \\
\hline 15 & 0.206 & 1.258 & 99.141 & & & & & & \\
\hline 16 & 0.152 & 0.859 & 100.000 & & & & & & \\
\hline
\end{tabular}

Final statistics in rotated component matrix using Varimax rotation method were present in Table 3. Small quadrangles in Table 3 explain six final components (or factors) based on their factor loadings. The most values are larger than 0.6, which is an acceptable value (Hu \& Bentler, 1999). 
Table 3

Final statistics in rotated component matrix

\begin{tabular}{|c|c|c|c|c|c|c|}
\hline & \multicolumn{6}{|c|}{ Rotated component matrix component } \\
\hline & 1 & 2 & 3 & 4 & 5 & 6 \\
\hline 1) Strategic marketing reasons of IT in SCM & -0.501 & 0.238 & 0.488 & 0.804 & 0.198 & -0.258 \\
\hline 2) Strategic economic reasons & -0.346 & 0.139 & 0.281 & 0.712 & -0.523 & 0.163 \\
\hline 3) Organizational strategic planning & 0.305 & -0.267 & -0.124 & 0.762 & -0.322 & -0.482 \\
\hline 4) Technological strategic planning & 0.298 & 0.498 & 0.262 & 0.662 & 0.492 & -0.486 \\
\hline 5) Virtual enterprise and IT in SCM & 0.805 & 0.113 & 0.356 & 0.122 & -0.294 & 0.314 \\
\hline 6) Partnership in Virtual enterprise & 0.658 & -0.106 & -0.247 & 0.477 & -0.592 & 0.074 \\
\hline 7) Purchasing in e-commerce & -0.018 & 0.682 & 0.292 & -0.111 & 0.006 & 0.508 \\
\hline 8) B2B e-commerce & 0.020 & 0.703 & 0.556 & 0.470 & -0.526 & -0.571 \\
\hline 9) Logistics in e-commerce & 0.278 & 0.744 & 0.166 & 0.253 & -0.403 & -0.283 \\
\hline 10) Organizational infrastructure for IT in SCM & 0.031 & -0.028 & 0.245 & -0.309 & 0.623 & 0.524 \\
\hline 11) Technological infrastructure for IT in SCM & -0.156 & 0.410 & 0.323 & -0.214 & 0.722 & 0.328 \\
\hline 12) Technology management in Knowledge and IT management in SCM & 0.012 & 0.591 & 0.825 & 0.091 & 0.577 & 0.022 \\
\hline 13) Education and training Knowledge and IT management in SCM & -0.356 & 0.424 & 0.727 & -0.230 & 0.345 & 0.580 \\
\hline 14) Organizational implementation of IT in SCM & -0.476 & 0.158 & 0.445 & 0.410 & 0.418 & 0.828 \\
\hline 15) Methodological implementation of IT in SCM & 0.088 & 0.334 & 0.069 & 0.572 & 0.221 & 0.765 \\
\hline 16) Human resource in implementation of IT in SCM & 0.407 & -0.503 & -0.341 & -0.495 & -0.210 & 0.632 \\
\hline
\end{tabular}

We have described these six final components and made a list as Table 4.

Table 4

List of the final components

\begin{tabular}{cc}
\hline Final component & Description of IT in SCM \\
\hline FC4 & Strategic planning for IT in SCM \\
FC5 & Infrastructure for IT in SCM \\
FC2 & Implementation of IT in SCM \\
FC3 & E-commerce \\
FC1 & Knowledge and IT management in SCM \\
\hline
\end{tabular}

\subsection{Preference of IT criteria in SCM}

Experts in SC determine a preference for adopting IT in their SCM with mean values of the IT in SCM criteria based on relevance and emergency. Relevance serves as a measure of the importance of the IT criteria in SCM and emergency presents a measure of the timing of IT criteria in SCM. The respondents estimate their IT criteria in SCM using a questionnaire sheet based on a Likert scaling. Table 5 demonstrates the mean values of the final component based on relevance and emergency.

Table 5

The mean values of the final component based on relevance and emergency

\begin{tabular}{ccccccc}
\hline $\begin{array}{c}\text { Mean } \\
\text { values }\end{array}$ & $\begin{array}{c}\text { Strategic planning } \\
\text { for IT in SCM }\end{array}$ & $\begin{array}{c}\text { Virtual } \\
\text { enterprise }\end{array}$ & E-commerce & $\begin{array}{c}\text { Infrastructure } \\
\text { for IT in SCM }\end{array}$ & $\begin{array}{c}\text { Knowledge and } \\
\text { IT management } \\
\text { in SCM }\end{array}$ & $\begin{array}{c}\text { Implementation } \\
\text { of IT in SCM }\end{array}$ \\
\hline $\begin{array}{c}\text { Emergency } \\
\text { Relevance }\end{array}$ & 4.28 & 3.27 & 3.64 & 4.14 & 3.77 & 3.86 \\
\hline
\end{tabular}

FC4 obviously indicates the highest value in emergency and relevance. The means of the FC5 followed that. FC6 accounts for the third highest measures in emergency and relevance. FC2, FC3 and FC1 indicate the lowest means. These high mean values explain that respondent firms have recognized the importance of each IT criteria in SCM.

\subsection{IT portfolio in SCM}

Finally, SC managers can develop an IT portfolio in SCM using mean values of few extracted components. Referring to the mean values list as Table 5, industrial companies develop their IT portfolio on the relevance-emergency matrix shown in Fig. 1. The relevance-emergency matrix defines four types of IT criteria units: 
1- High relevance and high emergency: Industrial firms often need heavy investment and pay more attention in IT criteria in SCM because they involve good opportunities for SCM in future.

2- High relevance and low emergency: These IT criteria need much investment and pay more attention, but it can be distributed for some periods.

3- Low relevance and high emergency: In this case industrial firms often require IT criteria to fast moving in 'innovative' markets where there is a volatile and unpredictable demand for short life cycle.

4- Low relevance and low emergency: These criteria can investigate in future ( Lee, \& Lee, 2011).

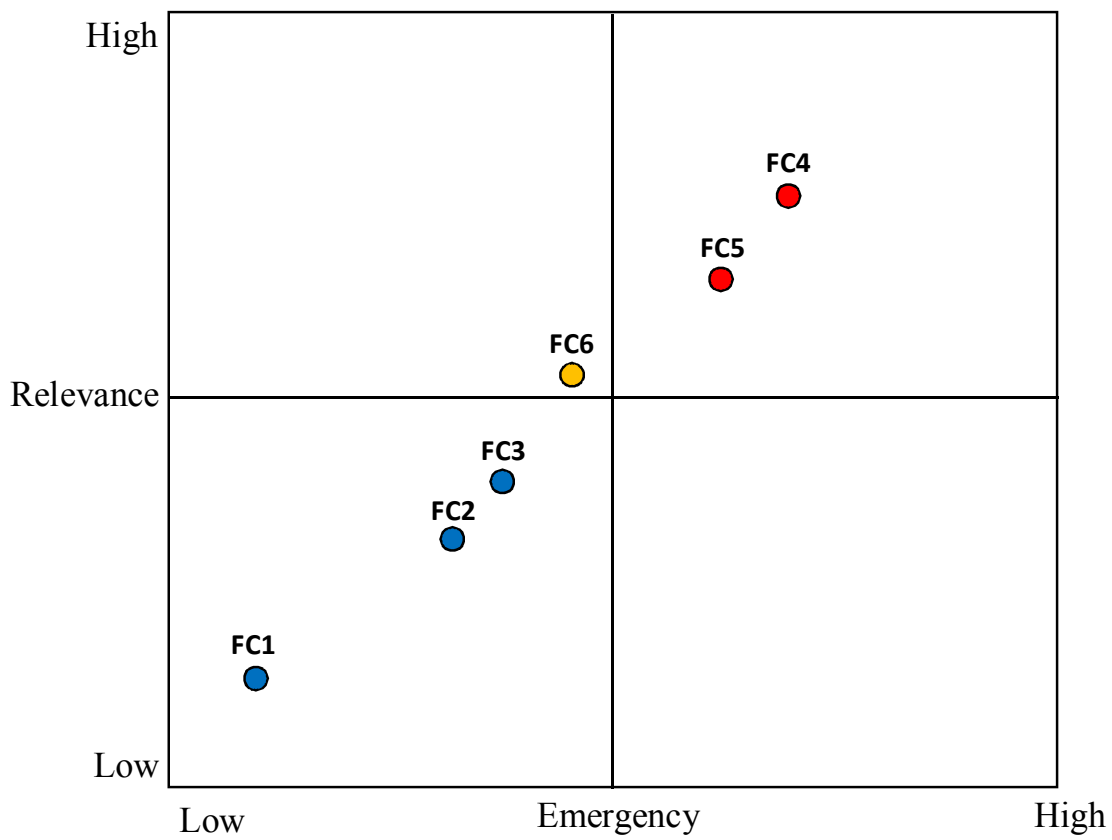

Fig.1. IT portfolio on the relevance-emergency matrix in SCM

Our finding in this numerical example illustrates that Strategic planning for IT in SCM (FC4) and Infrastructure for IT in SCM (FC5) lie in the area of high relevance and high emergency of the matrix and industrial firms need heavy investment and pay more attention in IT criteria in SCM because they involve good opportunities for SCM in future. Implementation of IT in SCM (FC6) lies in middle of relevance and emergency and In this numerical example industrial firms often require IT criteria to fast moving in 'innovative' markets where there is a volatile and unpredictable demand for short life cycle. E-commerce (FC2) Knowledge and IT management in SCM (FC3) and Virtual enterprise (FC1) are located in the area of low relevance and emergency and can investigate in future.

\section{Conclusion}

In this paper, we have used FA and PCA method to provide an analytical model for classification IT criteria in SCM for industries. Initially, we identified IT criteria associated with SCM and used from FA for explanation and classification of criteria. The results of this paper have provided six categories in the field of IT in SCM for industries and we have classified them. In this paper, based on relevance emergency matrix we suggested IT criteria in SCM portfolio and emphasize patterns and priorities of the IT in SCM for industries. Based on the results of matrix portfolio Strategic planning, Infrastructure 
and Implementation of IT in SCM were identified as the most important activities and E-commerce, Knowledge and IT management and Virtual enterprise were placed in the next category.

For future research, we propose to identify more IT criteria associated with SCM and use them for better decision making. Furthermore, the methodology of this study can be used in other fields of industries.

\section{Acknowledgement}

The authors would like to thank the anonymous referees for constructive comments on earlier version of this paper.

\section{References}

Andersen, T.J. (2001). Information technology, strategic decision making approaches and organizational performance in different industrial settings. Journal of Strategic Information Systems, $10,101-119$.

Angeles, R. (2009). Anticipated IT infrastructure and supply chain integration capabilities for RFID and their associated deployment outcomes. International Journal of Information Management, 29, 219 23.

Browne, J., \& Zhang, J. (1999). Extended and virtual enterprises - similarities and difference. International Journal of Agile Management Systems, 1, 30-36.

Byrd, T., \& Davidson, N. (2003). Examining possible antecedents of IT impact on the supply chain and its effect on firm performance. Information \& Management, 41, 243-255.

Cerpa, N., \& Verner, N.M. (1998). Case study: The effect of IS maturity on information systems strategic planning. Information \& Management, 34, 199-208.

Chae, B., Paradice, D., Courtney, J.F., \& Cagle, C.J. (2005). Incorporating an ethical perspective into problem formulation: implications for decision support systems design. Decision Support Systems, 40(2), 197-212.

Clements, P. (1997). Standards support for the virtual enterprise. Assembly Automation, 17(4), 307314.

Cooper, R.B., \& Zmud, R.W. (1990). Information technology implementation research: A technological diffusion approach. Management Science, 36(2), 123-139.

Daniels, S. (1998). The strategic use of information systems. Work Study, 47(5), 167-171.

Davenport, T.H. (1993). Process Innovation: Reengineering Work through Information Technology. Harvard Business School Press.

Davis, E.W., \& Spekman, R.E. (2004). The Extended Enterprise. Prentice Hall PTR, Upper Saddle River, NJ.

Gunasekaran, A., \& Chung, W.W.C. (2004). Special issue on supply chain management for the $21^{\text {st }}$ century organizational competitiveness. International Journal of Production Economics, 87(3), 209 212.

Gunasekaran, A., \& Ngai, E. (2003). Information systems in supply chain integration and management. European Journal of Operational Research, 159, 269-295.

Henderson, J. C., \& Venkataraman, N. (1993). Strategic alignment: Leveraging information technology for transforming organizations. IBM Systems Journal, 32(1), 4-16.

Hu, L., \& Bentler, P.M. (1999). Cutoff criteria for fit indexes in covariance structure analysis: Conventional criteria versus new alternatives. Structural Equation Modeling, 6, 1-55.

Jayaram, J., Shawnee, K.V., \& Droge, C. (2000). The effects of information system infrastructure and process improvements on supply-chain time performance. International Journal of Physical Distribution \& Logistics Management, 30(3/4), 314-330.

Jolliffe, I.T. (2002). Principal component analysis. Springer series in statistics (2nd) Springer, New York.

Kim, J.O., \& Mueller, C.W. (1987). Introduction to factor analysis. Sage, Beverly Hills, p57. 
Lancioni, R.A., Smith, M.F., \& Oliva, T.A. (2000). The role of the Internet in supply chain management. Industrial Marketing Research, 29(1), 54-65.

Lee, H.L. (2002). Aligning Supply Chain Strategies with Product Uncertainties. California Management Review, 44(3), 104-119.

Lee, Y., \& Lee, H. (2011). Application of factor analysis for service R\&D classification: A case study on the Korean ICT industry. Expert Systems with Applications, 38, 2119-2124.

Leidner, D.E. (2010). Globalization, culture, and information: Towards global knowledge transparency. Journal of Strategic Information Systems, 19(2), 69-77.

Li, G., Yang, H., Sun, L., \& Sohal, A.S. (2009). The impact of IT implementation on supply chain integration and performance. International Journal of Production Economics, 120(1), 125-138.

Lockamy, A., \& Smith, W.I. (1998). Strategic alignment approach for effective business process reengineering: Linking strategy, processes and customers for competitive advantage. International Journal of Production Economics, 50, 141-153.

Manecke, N., \& Schoensleben, P. (2004) Cost and benefit of Internet-based support of business processes. International Journal of Production Economics, 87(3), 213-229.

McIvor, R., Humphreys, P., \& Huang, G. (2000) Electronic commerce: Re-engineering the buyersupplier interface. Business Process Management Journal, 6(2), 122-138.

Naim, M.M. (2006). The impact of the net present value on the assessment of the dynamic performance of e-commerce enabled supply chains. International Journal of Production Economics, 104(2),382393.

Ngai, E.W.T., Lai, K.H., \& Cheng, T.C.E. (2008) Logistics information systems: The Hong Kong experience. International Journal of Production Economics, 113(1), 223-234.

Parasuraman. A., Grewal, D., \& Krishnan, R. (2004). Marketing research, Houghton Mifflin Company, Boston, New York

Pawar, K.S., \& Driva, H. (2000). Electronic trading in the supply chain: A holistic implementation framework. Logistics Information Management, 13(1), 21-32.

Rai, A., Patnayakuni, R., \& Seth, N. (2006) Firm performance impacts of digitally enabled supply chain integration capabilities. MIS Quarterly, 30(2):225-246

Radjou, N. (2003). U.S. manufacturers' supply chain mandate. World Trade, 16(12), 42-46.

Rogers, D.S., Daugherty, P.J., \& Stank, T.P. (1993). Enhancing service responsiveness: the strategic potential of EDI. Logistics Information Management, 6, 27-32.

Samuel, K.E., Goury, M.L., Gunasekaran, A., \& Spalanzani, A. (2011). Knowledge management in supply chain: An empirical study from France. Journal of Strategic Information Systems, 20, 283 306.

Sarkis, J., \& Sundararaj, R.P. (2002). Evolution of brokering paradigms in e-commerce enabled manufacturing. International Journal of Production Economics, 75, 21-31.

Sarkis, J., \& Talluri, S. (2004). Evaluating and selecting e-commerce software and communication systems for a supply chain. European Journal of Operational Research, 159(2), 318-329.

Scott, G.J. (1996). Expanding the role of the project director as the CIO in the information technology industry. Project Management Journal, 5, 15.

Simchi-Levi, D., Kaminsky, P., \& Simchi-Levi, E. (2000). Designing and Managing the Supply Chain: Concepts, Strategies and Case Studies. McGraw-Hill International Edition, Singapore

Smith, L.I. (2002). A tutorial on principal components analysis. $<$ http://www.cs.otago.ac.nz/cosc453/student_tutorials/principal_components.pdf $>$

Su, Y., \& Yang, C. (2010). A structural equation model for analyzing the impact of ERP on SCM. Expert Systems with Applications. 37, 456-469

Tippins, M.J., \& Sohi, R.S. (2003). IT competency and firm performance: Is organizational learning a missing link?. Strategic Management Journal, 24(8), 745- 761.

Turowski, K. (2002). Agent-based e-commerce in case of mass customization. International Journal of Production Economics, 75 (1-2), 69-81. 
Wadhwa, S., \& Saxena, A. (2005). Knowledge management based supply chain: an evolution perspective. Global Journal of e-Business and Knowledge Management, 2(2), 13-29.

Wu, F., Mahajan, V., Balasubramanian, S. (2003). An analysis of e-business adoption and its impact on business performance. Journal of Academy of Marketing Science, 31, 435-447.

Zhang, C., \& Dhaliwal, J. (2009). An investigation of resource-based and institutional theoretic factors in technology adoption for operations and supply chain management. International Journal of Production Economics, 120:252-269. 